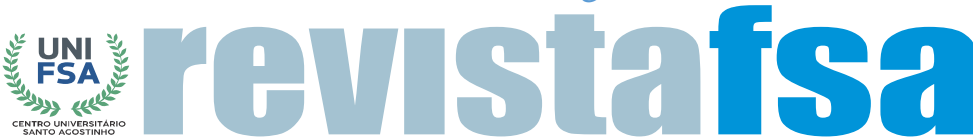 \\ www4.fsanet.com.br/revista
}

Rev. FSA, Teresina, v. 18, n. 12, art. 7, p. 124-138, dez. 2021 ISSN Impresso: 1806-6356 ISSN Eletrônico: 2317-2983 http://dx.doi.org/10.12819/2021.18.12.7

\section{Ilha De Páscoa: Experiências do Passado Como Meio Para Pensar a Crise Ambiental} Contemporânea

\section{Easter Island: Past Experiences as a Means to Think About the Contemporary Environmental Crisis}

Douglas Fernando dos Santos Godoy Doutor em Ciências Sociais pela Universidade Estadual Paulista Professor do Instituto de Educação, Ciência e Tecnologia de São Paulo E-mail: douglasgodoy1@gmail.com
Endereço: Douglas Fernando dos Santos Godoy IFSP Campus Presidente Epitácio: Rua José Ramos Júnior, 27-50 - Jardim Tropical, CEP 19470-000, Presidente Epitácio - SP. Brasil.

\section{Editor-Chefe: Dr. Tonny Kerley de Alencar} Rodrigues

Artigo recebido em 13/12/2021. Última versão recebida em 16/12/2021. Aprovado em 17/12/2021.

Avaliado pelo sistema Triple Review: a) Desk Review pelo Editor-Chefe; e b) Double Blind Review (avaliação cega por dois avaliadores da área).

Revisão: Gramatical, Normativa e de Formatação 


\title{
RESUMO
}

$\mathrm{O}$ artigo se concentrou em investigar as experiências ambientais da antiga sociedade da Ilha de Páscoa, a fim de que estas pudessem iluminar a análise da sociedade moderna em seu relacionamento com a natureza nos dias atuais. Isso demandou, inicialmente, consultas ao livro Colapso, de Jared Diamond, que detalhou magistralmente a história de Páscoa, além de pesquisa bibliográfica sobre processos sociais de competição, cooperação e conflito. Revelouse que a sociedade de Páscoa, mesmo em períodos mais dramáticos de sua crise ambiental, não ignorou a competição, competindo de maneira exacerbada, como se não percebesse que era este comportamento que a conduzia para o colapso. Por força principalmente do capitalismo e do industrialismo, a sociedade moderna trilha caminho muito parecido àquele escolhido pelos pascoenses, com indivíduos e coletividades competindo fervorosamente, desta vez por capital, impondo com isso altos custos à natureza, sem aparentemente respeitar seus limites físicos.

Palavras-Chave: Sociedade Antiga. Colapso. Crise Ecológica. Meio Ambiente.

\begin{abstract}
The article focused on investigating the environmental experiences of the ancient society of Easter Island, so that they could illuminate the analysis of modern society in its relationship with nature today. This initially required consultation with the book Colapso, by Jared Diamond, which masterfully detailed the history of Easter, in addition to bibliographical research on social processes of competition, cooperation and conflict. It was revealed that Easter society, even in the most dramatic periods of its environmental crisis, did not ignore competition, competing in an exacerbated manner, as if it did not realize that it was this behavior that led it to collapse. Mainly due to the capitalism and industrialism, the modern society trails a path very similar to the one chosen by the Easterists, with individuals and collectivities competing fervently, this time for the capital, thus imposing high costs to nature, without apparently respecting its physical limits.
\end{abstract}

Keywords: Ancient Society. Collapse. Ecological Crisis. Environment. 


\section{INTRODUÇÃO}

A relação entre homem e natureza sempre foi marcada pelo conflito. Episódios históricos, como a quase extinção do povo polinésio que habitou a denominada Ilha de Páscoa em decorrência do uso irracional de recursos naturais, bem como a severa exploração florestal ocorrida no Brasil colonial, ilustram o caráter crítico desta relação. Historicamente, na maior parte das vezes sem respeitar os direitos intrínsecos da natureza e das espécies que nela se abrigam, tampouco os limites físicos do planeta, o homem se apropriou dos recursos naturais, criou objetos e produziu alimentos e, a partir disso, satisfez toda ordem de interesses, dos mais elementares e inofensivos aos mais supérfluos e devastadores para o meio ambiente.

Por muitos séculos, os impactos da intervenção humana na natureza não provocaram grandes repercussões na sociedade moderna - notadamente porque a natureza, imensa diante do reduzido contingente humano nos tempos mais longínquos da modernidade, mostrou-se aparentemente mais forte do que frágil, provocando no homem o fatídico entendimento de que devesse ser objeto de dominação e não de preservação - mas a partir do último século e, mais acentuadamente nas últimas décadas, relatos científicos em documentos como Our Common Future, de Brundtland, e The Limits to Growth, do Clube de Roma, repercutiram globalmente a sensação de que a ação do homem ao longo da história culminou em um estado de crise ambiental, caracterizada por problemas como o aquecimento global, a perda de biodiversidade e a poluição hídrica.

Por isso mesmo, o grande desafio dos tempos mais recentes tem sido apontar caminhos virtuosos para a superação da crise ambiental. Cientistas das mais diversas correntes do pensamento têm se empenhado nesta difícil tarefa. Eles se organizam basicamente em duas principais linhas de pensamento: uma parte dos cientistas tende a pensar que a solução para a crise ambiental estaria irremediavelmente na dissolução do industrialismo e/ou do capitalismo; outra parte argumenta que é possível resolver a crise ambiental sem romper com o industrialismo e/ou com o capitalismo, pressupondo que estas instituições irão se adaptar às contingências atuais. Muitos cientistas chegam a estas conclusões analisando unicamente a sociedade moderna, ignorando as experiências de sociedades antigas com o meio ambiente. Com isso em vista, procurou-se conhecer as experiências ambientais de uma sociedade do passado, a sociedade da Ilha de Páscoa, a fim de que este caso possa iluminar a análise da sociedade moderna e de seu relacionamento com a natureza. Esta abordagem alternativa pode fornecer elementos importantes para a reflexão acerca de duas questões cruciais nos dias atuais, que são: o que conduz a sociedade moderna a uma crise ambiental? E, além disso, qual 
o melhor caminho para a superação desta problemática ecológica? Tem-se, com isso, a pretensão de oferecer algumas reflexões na direção de contribuir para a geração de respostas para estas duas questões.

$\mathrm{O}$ artigo se encontra organizado em três seções, além da introdução e das considerações finais. Na primeira seção, tratar-se-á conceitualmente do tema competição. Isso se mostra necessário, porque a competição está fortemente presente na sociedade moderna e, como se verá mais adiante, foi determinante para a quase extinção da sociedade da Ilha de Páscoa. Em seguida, de maneira sintética, o propósito será o de apresentar a história do povo pascoense, destacando principalmente o papel da competição na crise ambiental pela qual passou esta sociedade. Por fim, na terceira seção, analisar-se-á a sociedade moderna e seu relacionamento com o meio ambiente, a fim de que se possa compreender o que levou esta sociedade a um estado de crise ambiental e, ainda, à luz das experiências da Ilha de Páscoa, apontar um caminho virtuoso para a superação desta problemática.

\section{REFERENCIAL TEÓRICO}

\subsection{O Processo Social de Competição}

Não se mostra necessário mergulhar profundamente nos registros da memória para se encontrar uma coleção de experiências que expressa processos de interação social. É suficiente observar ações simples e corriqueiras, como ajudar um idoso a atravessar a rua, concorrer por uma vaga no estacionamento do shopping ou mesmo discutir com integrantes da família sobre quem irá lavar a louça. Estas interações representam apenas uma pequena fração de tudo o que acontece diariamente. Fato é - e isso precisa ser destacado - que estas ações individuais que, a priori, ${ }_{2}$ podem parecer até mesmo inofensivas, são unidas a outras ações de centenas de milhares de pessoas do globo todos os dias e, assim, tornam-se coletivas e definidoras da maneira como cada sociedade se relaciona com sua espécie, com outras espécies e com a natureza.

De acordo com Parks e Burgess (2014), o processo social é composto por quatro grandes formas, que são: competição, conflito, acomodação e assimilação. A fim de seguir os propósitos desta pesquisa, iremos abordar principalmente o conceito de competição e, oportunamente, tratar-se-á dos temas cooperação e conflito. Competição, segundo Ogburn e Nimkoff (1965, p.238), representa uma "forma fundamental de luta social que ocorre todas as vezes em que há um suprimento insuficiente de tudo quanto deseja o ser humano". Partindo da ideia de que "todos não podem possuir a quantidade que desejam de alguma coisa" 
(OGBURN; NIMKOFF, 1965, p.238), percebe-se que a competição está sempre presente na sociedade, seja em maior ou menor grau, sendo que a motivação para a competição, em nível específico, está ligada aos interesses individuais e, em nível geral, aos interesses da coletividade.

O processo social de competição, assim como o de cooperação, são fenômenos naturais, hereditários, ou seja, acompanha o ser humano desde os primórdios de sua existência, podendo ser facilmente percebido durante a infância. Os jogos escolares, os quais reúnem crianças e adolescentes, são ótimas oportunidades para se constatar isso. Certamente o que se assistirá são competições assíduas, nas quais todas as forças individuais e coletivas serão depositadas para alcançar a glória e, assim, evitar a derrota. E, em meio a estas competições, não faltarão casos em que a glória se deu, não apenas pela capacidade competitiva dos indivíduos, mas também - e, talvez, principalmente - pela capacidade cooperativa das crianças. Não é diferente com os adultos. Em qualquer tipo de sociedade, seja antiga ou contemporânea, não faltam registros (e nunca faltarão) de competição e de cooperação entre adultos. Homens, por exemplo, competem com outros desde os períodos mais remotos pela conquista de territórios; e, igualmente antigo, são os atos de cooperação para a realização de grandes obras, como as Pirâmides do Egito. A competição e a cooperação, deste modo, são parte e fazem parte da vida em sociedade.

De acordo com Ogburn e Nimkoff (1965), as razões que sustentam as competições são diversas, podendo ser por necessidades básicas, como a necessidade de se alimentar; pelo simples prazer de competir; por segurança; ou mesmo por luxo, poder, posição social, fama, etc. Em outros termos, a motivação pode se dar por necessidade de subsistência - e, neste caso, se a competição ocorrer em condições de recursos escassos, a tendência é o conflito - ou por questões econômicas, políticas, sociais, científicas, esportivas, etc. Os conflitos por água na Ásia exemplificam adequadamente a competição motivada pela subsistência e por razões econômicas. A China tem ameaçado construir barragens ao longo do rio Brahmaputra. $\mathrm{O}$ problema é que este rio banha e é fundamental para o abastecimento público e para o uso agrícola e fabril na Índia e no Paquistão. Se as barragens de fato forem construídas, prejudicarão o fluxo de água para estes países e, consequentemente, o bem-estar das sociedades e os seus resultados econômicos. Decerto que esta competição por um bem comum, se persistir, poderá levar a conflitos mais sérios, como guerras entre as nações envolvidas. Isso não seria nada excepcional, visto que os registros históricos dão conta de que a competição, na maioria das vezes por poder e/ou posição social, culmina em conflitos marcados pela irracionalidade humana. 
$\mathrm{Na}$ sociedade moderna, a luta se dá predominantemente por razões econômicas. Conforme salientam Ogburn e Nimkoff (1965), nesta sociedade o interesse do indivíduo é obter melhores posições ao longo de sua carreira e, espera-se, em consequência disso, retornos significativos de capital (dinheiro). Eles argumentam que nesta lógica a medida do sucesso nada mais é do que a quantidade de dinheiro que o indivíduo consegue acumular ao longo da vida. A acumulação de capital passa a fazer sentido para o indivíduo, pois é por meio dela que ele poderá satisfazer suas necessidades e desejos, como adquirir um casarão, carros sofisticados, obras de artes, alimentos de melhor qualidade, etc. Ocorre que para alcançar posições de destaque na carreira atualmente, o indivíduo necessariamente terá de se submeter e ser bem-sucedido em inúmeros processos de competição. Trata-se de um percurso longo de competição que ocupa boa parte do tempo de existência do indivíduo e que, na maior parte das vezes, não pode ser transposto integralmente. Ao final do trajeto, o indivíduo poderá notar que, embora tenha buscado satisfazer todas as suas necessidades e desejos em cada minuto de sua vida, conseguiu apenas realizar parte daquilo que foi planejado.

É importante destacar que nem sempre a competição envolve diretamente os competidores. Por exemplo, em uma corrida de cavalo, os animais são os meios pelos quais os indivíduos realizam a competição. Os meios de maior destaque para fins econômicos na sociedade moderna são as empresas comerciais e industriais. Indivíduos adquirem empresas e as colocam para funcionar. Este tem sido o desejo de muitas pessoas na modernidade. Com isso, cada indivíduo tem condições de potencializar os seus ganhos a um nível que, individualmente, dependendo tão somente de sua força de trabalho, não poderia ser alcançado. Hoje, por exemplo, temos um sem número de empresas comerciais e industriais no mundo e de todos os tamanhos imagináveis. Algumas são pequenas e de propriedade individual; outras são grandiosas e de propriedade de uma porção de grupos de indivíduos, como é o caso das companhias de capital aberto. Impulsionadas pelo desejo do cidadão capitalista pelo lucro, elas competem fervorosamente e estão sempre em busca das melhores condições de combate. As melhores competidoras geralmente são aquelas capazes de acumular a maior quantia em lucro, proporcionalmente ao seu tamanho, e, assim, aumentar o retorno financeiro e o consequente potencial de consumo de seus proprietários. Em nível mais amplo, todos estes movimentos empresariais irão contribuir para o alcance daquilo que determina não apenas a continuidade do capitalismo, mas também o seu êxito: o crescimento econômico.

Como se nota, a competição está muito presente no capitalismo, mas isso não significa que inexista cooperação em seu meio. Aliás, como revela Ogburn e Nimkoff (1965), sociedades podem ser competitivas e cooperativas ao mesmo tempo. Por um lado, significa 
dizer que é possível que os integrantes de uma determinada sociedade trabalhem de maneira competitiva para alcançar um fim cooperativo. Principalmente em cooperativas, a cooperação competitiva é muito comum. Parte-se do princípio de que todos precisam competir internamente, forçando, assim, maiores níveis de produção, que resultarão em mais benefícios para todos. De outro, significa dizer que é possível que os integrantes de uma determinada sociedade trabalhem de maneira cooperativa para alcançar um fim competitivo. O que se pode aqui denominar de competição cooperativa pode facilmente ser encontrada nas grandes fábricas modernas, nas quais recorrentemente tem sido reconhecido que a cooperação interna também apresenta contribuições para o alcance de melhores condições para a competição.

Por ser um fenômeno natural, a competição e a cooperação sempre estarão presentes em qualquer sociedade. Ocorre que algumas sociedades se tornam predominantemente competitivas ou cooperativas, como pode ser constatado nos estudos de Mead (1961). De acordo com Ogburn e Nimkoff (1965), a experiência humana tem a maior importância nesta definição. É através da cultura que os objetivos primordiais de toda sociedade são transmitidos às gerações futuras. Então, o tipo de sociedade a ser formada, ou seja, predominantemente competitiva ou cooperativa, é reflexo dos objetivos fundamentais de cada sociedade. Diante disso, a educação - seja ela formal, familiar e/ou religiosa - assume total importância para a promoção de transformações sociais. A sociedade de Páscoa - caso que será apresentado na próxima seção - mesmo estando em situação de catástrofe, não alterou seus objetivos primordiais e, por isso mesmo, conheceu os mais severos efeitos da competição. É importante notar que a pretensão aqui não é afirmar que a competição conduz inevitavelmente ao caminho da catástrofe, mas de dizer que a competição, principalmente quando exagerada, pode levar o ser humano a cometer atrocidades, até mesmo contra si, e isso, quando levado a cabo pela sociedade, pode produzir danos à natureza de difícil reversão.

\section{A SOCIEDAdE dE PÁSCOA E O MEIO AMBIENTE}

Páscoa é o pedaço de terra habitado mais isolado do mundo. Trata-se de uma ilha localizada no Oceano Pacífico, a 3.700 quilômetros da costa do Chile e a 2.000 quilômetros das ilhas de Pitcairn, na Polinésia. A ilha tem $170 \mathrm{~km}^{2}$, possui clima ameno, topografia suave e uma precipitação de $1.300 \mathrm{~mm}$ anuais. No território pascoense, existem três vulcões inativos: Poike (o mais velho), Rano Kau e Terevaka. O nome páscoa foi dado pelo descobridor da Ilha, o explorador Holandês Jacob Roggeveen, pelo motivo de o mesmo ter 
avistado essas terras no domingo de páscoa, mais especificamente em 5 de abril de 1722 . (DIAMOND, 2009).

A ocupação da Ilha de Páscoa constitui um grande mistério, justamente porque há vestígios de ocupação desde 900 d.C, embora nesse período não se dispunha de grandes navios, apenas de pequenas canoas, tampouco de aparelhagem de navegação. Por isso, a questão que se coloca frequentemente é como foi possível, com pequenas embarcações, cruzar o Oceano Pacífico e atingir a Ilha de Páscoa depois de no mínimo 2.000 quilômetros de viagem? Fato é que, apesar da aparente impossibilidade, ficou comprovado ser possível alcançar a ilha de páscoa com pequenas embarcações. Em 1999, uma pequena canoa saiu de Mangareva e reproduziu a viagem dos colonizadores de Páscoa, alcançando a ilha 17 dias depois de sua partida (DIAMOND, 2009).

Gradativamente, depois de sua colonização, a população de Páscoa foi aumentando. Estima-se que chegaram a viver na ilha de 6 a 30 mil pessoas. Os pascoenses sobreviviam basicamente de práticas agrícolas, como produção de batatas-doces, inhame, taro, bananas e cana-de-açúcar, da criação de galinhas (único animal doméstico) e da caça de aves marinhas, terrestres, golfinhos e ainda, com menor participação na dieta, do pescado. Tradições orais dos insulares, bem como de pesquisas arqueológicas, sugerem que a ilha foi dividida em 12 territórios, cada um desses territórios sob o domínio de um clã ou grupo de linhagem. Cada clã possuía um chefe e uma plataforma (ahu) usada como suporte para estátuas de pedra (moais). Os clãs, embora rivais, competiam pacificamente, buscando superar um ao outro na construção de estátuas. Apesar da divisão em territórios e da existência de um chefe para cada clã, constatou-se que os territórios eram integrados religiosamente e de certa maneira econômica e politicamente, com a existência de um chefe supremo. Isso certamente se fez necessário em consequência de os recursos estarem espalhados pelos diversos territórios, gerando uma relação de dependência entre os clãs. (DIAMOND, 2009).

A Ilha de Páscoa, hoje, é conhecida pelo grande número e tamanho de suas estátuas. Foram identificadas na ilha 300 plataformas, muitas delas pequenas e sem estátuas, mas cerca de 113 plataformas possuíam estátuas, sendo 25 especialmente grandes e elaboradas, algumas com peso aproximado de 9.000 toneladas. Em relação às estátuas, foram inventariadas 887, das quais metade se encontra na pedreira de Rano Raraku, a principal e a que contém as melhores pedras da ilha para esculpir. A estátua padrão possuía quatro metros de altura e pesava cerca de 10 toneladas. No entanto, foram encontradas estátuas maiores, como a denominada Paro, a maior da ilha, com altura de 10 metros e peso de 75 toneladas. Pode-se ainda citar as estátuas que não puderam ser terminadas, dentre elas uma com 21 metros de 
comprimento com peso aproximado de 270 toneladas. As estátuas, que a priori eram construídas para homenagear ancestrais de membros das elites da ilha, tornaram-se o principal meio de demonstração de poder dos clãs dos 12 territórios de Páscoa (DIAMOND, 2009).

Ao longo do desenvolvimento histórico de Páscoa, a competição acirrou-se e as estátuas produzidas passaram a ser progressivamente maiores. Contudo, os empreendimentos pascoenses se mostravam algo irracional, especialmente em consequência dos altos custos associados à criação de estátuas e de sua locomoção até as plataformas. Por exemplo, as necessidades alimentares em função da construção de estátuas aumentavam em $25 \%$, isso porque era preciso alimentar escultores, equipes de transporte e clãs que permitiam o transporte de estátuas por seus territórios, todos pagos com alimentos. Além disso, a operação de transporte exigia um alto volume de cordas (feitas de casca de árvores) e de madeira para a construção de trilhos pelos quais se transportariam por até 14 quilômetros estátuas produzidas na pedreira Rano Raraku. Todo esse dispêndio natural sustentou as competições entre clãs rivais e as suas necessidades de demonstração de poder por meio da construção de estátuas cada vez mais imponentes. (DIAMOND, 2009).

As consequências dessas ações foram sentidas mais vigorosamente durante o século XVI e XVII. Em 1722, quando Roggeveen desembarcou em Páscoa, não avistou nenhuma árvore com mais de três metros nessa ilha, local que no passado continha uma floresta diversificada, com Palmeiras que chegavam a medir mais de 20 metros de altura. O desmatamento aumentou na mesma proporção em que cresceu a produção de estátuas e acabou por extinguir grande parte das espécies florestais que naquele momento histórico existiam naquele território. Fora isso, a extinção de florestas causou outros problemas para os pascoenses. Sem florestas, o solo perdeu nutrientes e a proteção contra o Sol, de modo que isso impactou na produção de alimentos; os animais terrestres que dependiam da floresta para sobreviver desapareceram; canoas para navegação não puderam mais ser fabricadas, o que impactou na captura de golfinhos e peixes oceânicos para a alimentação. Neste período, aumentou-se a participação da carne de rato na dieta pascoense. Nos limites dessa crise ambiental, o povo pascoense não teve outra saída a não ser o canibalismo. Em razão disso, a sociedade começou a se reduzir drasticamente. Em 1872, havia apenas 111 insulares na ilha. (DIAMOND, 2009).

Como se pôde observar, embora em uma ilha, a sociedade pascoense dispunha de muitos recursos naturais. Desde que usados racionalmente, estes recursos poderiam garantir a sobrevivência da sociedade sem que fosse necessário passar por situações de catástrofe. Fato é que a sociedade optou pelo caminho alternativo. A sociedade devastou os recursos naturais da 
ilha para se agarrar a um processo de competição sem fim entre os clãs, marcado pela construção de estátuas cada vez maiores. Mesmo nos momentos mais dramáticos, quando os alimentos se escassearam, eles permaneceram competindo. Fica notório, assim, que a competição teve forte participação no que ocorreu em Páscoa, levando a sociedade a cometer irracionalidades de difícil compreensão. Tendo em vista a experiência de Páscoa na condição de sociedade predominantemente competitiva, torna-se interessante investigar a realidade da sociedade moderna, procurando descobrir o que conduz esta sociedade a um estado de crise ambiental e qual seria o caminho mais virtuoso para a superação da crise ambiental. Procurarse-á abordar estas questões na próxima seção.

\section{A SOCIEDADE MODERNA E O MEIO AMBIENTE}

Conjuntamente, o industrialismo, o capitalismo e a ciência atuaram para moldar a sociedade moderna e para definir a relação desta com o meio ambiente. $\mathrm{O}$ industrialismo aumentou significativamente a capacidade do homem de produzir mercadorias. Para isso, contou com o apoio da tecnologia. Ela forneceu condições para que se efetivasse a transição de um processo de produção artesanal, no qual cada produto era confeccionado individualmente, no tempo do artesão e com ferramentas rudimentares, para o processo de produção industrial, no qual a produção passa a ser feita em massa, com o uso de tecnologias revolucionárias à época, como a máquina a vapor e o tear mecânico. Fora isso, introduziramse no processo produtivo algumas metodologias que contribuíram para impulsionar a produção, dentre as quais, talvez a principal delas, a divisão de tarefas.

O capitalismo, amparado no princípio de acumulação de capital, alterou significativamente o modo de vida das pessoas. Mergulhou a sociedade em um sistema complexo de trocas, no qual sequer a força de trabalho individual escapa, sendo também uma mercadoria. Troca-se, nas empresas, força de trabalho por dinheiro e, subsequentemente, o dinheiro por novas mercadorias das empresas. A cada nova rodada de trocas, aumenta-se o potencial de produção de mercadorias em decorrência dos ganhos acumulados no ciclo produtivo anterior, o que, consequentemente, demanda a ampliação do mercado consumidor, assim como de suas necessidades e desejos, para garantir a absorção do normal e do adicional de produção.

Da revolução industrial para cá, o industrialismo e o capitalismo se ampararam fortemente nas descobertas científicas e nas inovações tecnológicas para se desenvolverem. Fábricas modernas são quase integralmente automatizadas, com presença pouco significativa de pessoas no processo produtivo. Em muitas indústrias, a função dos operários se resume à 
inserção de matérias-primas na maquinaria, ajustes das máquinas e, ao final, a retirada do produto acabado. A fase de processamento, na qual as matérias-primas são misturadas para dar forma ao produto final, em muitos casos dispensa a presença humana. Além disso, apenas para exemplificar, a ciência e a tecnologia revolucionaram os meios de comunicação. Hoje se pode comprar quase tudo que se deseja pela internet. Apenas estes exemplos são suficientes para evidenciar como a ciência e a tecnologia contribuíram para a consolidação do modo industrial-capitalista de produção como sistema dominante no mundo, demonstrando a existência de, como Max Weber chamaria, afinidades eletivas entre industrialismo, capitalismo e a ciência moderna.

Em meio ao industrialismo e ao capitalismo, o objetivo primordial do indivíduo e da sociedade não poderia ser outro, a não ser a acumulação de capital. Este ideal tornou a sociedade moderna predominantemente competitiva. A luta ocorre basicamente por melhores condições de produção, melhores condições de comercialização e melhores condições de consumo. Basicamente, o intento principal de quem produz e comercializa é a redução de custos sem perder a qualidade dos produtos. A redução de custos terá sido bem-sucedida, se ela se apresentar superior à do concorrente. Com custos reduzidos, a empresa em questão pode produzir e/ou comercializar seus produtos pelo mesmo preço praticado no mercado, sem alteração de qualidade, mas com lucro maior. Por outro lado, a intenção principal de quem consome é adquirir produtos e/ou serviços para satisfazer suas necessidades e desejos, sempre com as melhores condições de compra. Por exemplo, o consumidor pode optar pela loja X, em vez de $\mathrm{Y}$, porque esta vende o mesmo produto encontrado na loja Y com preço menor ou com melhores condições de pagamento. Em síntese, o que o consumidor procura é um plus que irá ajudá-lo no seu propósito de acumular capitais, geralmente para fazer compras de maior monta, como uma casa ou um carro. Fato é que, estando produzindo, comercializando ou consumindo, a competição está sempre e intensamente presente na sociedade moderna.

Fundou-se, assim, uma sociedade profundamente produtivista e consumista. Na sociedade moderna, até mesmo como uma medida de adequação ao modo de produção dominante, os indivíduos tiveram as suas necessidades e desejos alargados. No passado, as pessoas se contentavam em satisfazer suas necessidades básicas, ao passo que os indivíduos da modernidade possuem necessidades e desejos ilimitados. Todos os dias a sociedade é submetida a novas mercadorias e processos que acabam por criar novas necessidades e desejos. Algumas mercadorias e processos, a despeito de serem exageradamente excêntricas, contam com o interesse de consumidores. Recentemente, uma grande rede varejista mundial disponibilizou para comercialização no seu website uma máquina que poderia ser utilizada 
para acariciar gatos. A mesma loja também ofereceu a opção de compra de sorvetes para astronauta. Se quisermos ir mais adiante, atualmente é possível depositar um corpo (morto) para congelamento (criogenia) para possível ressuscitação no futuro; ou então, modificar geneticamente o DNA de embriões humanos para evitar doenças ou mesmo para garantir características físicas desejáveis pelos pais.

Exemplos como os supracitados incitam uma questão importante: o objetivo primordial da sociedade moderna, que é a acumulação de capital, estaria levando os indivíduos a uma competição exagerada e, consequentemente, ao cometimento de irracionalidades? Quanto a isso, apenas os exemplos citados acima bastam para não restar nenhuma dúvida. Qual é o sentido de possuir um acariciador de gatos, comprar um sorvete para astronauta ou mesmo de pretender viver pela eternidade em um planeta que tende à superpopulação? Assim como ocorreu na Ilha de Páscoa, os resultados destas irracionalidades têm levado o planeta a uma crise ambiental sem precedentes, marcado por devastação florestal, extinção de espécies, poluição da água, do solo e do ar, mudanças climáticas e muitos outros problemas.

Diante da crise ambiental que enfrentaram, os pascoenses acreditaram que, por ação divina, tudo iria se resolver e continuaram competindo fervorosamente. Isso quase resultou na extinção da sociedade. Boa parte da sociedade moderna, diante da degradação do meio ambiente, deposita grande confiança na ciência, na tecnologia e na modernização reflexiva. Faz todo o sentido, afinal a ciência e a tecnologia têm evoluído muito nos últimos tempos, criando soluções para produção, comercialização e consumo mais eficientes, além de mecanismos para recuperação de ambientes naturais. Fala-se em indústrias mais tecnológicas e menos poluentes, fabricação de produtos mais eficientes, menor necessidade de utilização de recursos naturais, e assim por diante. Além disso, aos poucos a sociedade está adotando hábitos mais responsáveis ambientalmente, como o menor consumo de água e energia elétrica, a interrupção da ingestão de carnes e a reutilização de embalagens. Cabe destacar que nenhuma das medidas citadas aparenta estar interessada em interromper a competição, mas sim adotar um modo de competição que não ignore aspectos ecológicos. Sendo assim, o objetivo primordial da sociedade moderna de acumulação de capital permaneceria inalterado.

É neste ponto que reside o grande problema. A manutenção do objetivo primordial da sociedade moderna de acumular capital implica a continuidade da competição exagerada e tudo de negativo que decorre dela, inclusive a degradação ambiental. Diante destas condições, as melhorias em prol do meio ambiente decorrentes dos avanços científicos e tecnológicos seriam ao longo do tempo superadas pela força produtivista e consumista incitada pela 
competição sob uma lógica capitalista e industrial. Basta perceber que o capital excedente das empresas, em um cenário de competição por acumulação de capitais, seria novamente aplicado no processo produtivo com fins a criar inovações em produtos e serviços. Isso geraria mais capital que, por sua vez, estimularia mais produção e consumo. Não existe outro fim para o capital dentro do sistema capitalista que não resulte em mais consumo e produção. A produção e o consumo tendem a aumentar, porque o capitalismo sobrevive do crescimento econômico. Portanto, de nada adianta ter uma sociedade inteira consumindo produtos ecológicos ou adotando hábitos ecologicamente corretos, se a competição permanece exagerada, potencializando a produção e o consumo e, consequentemente, a degradação ambiental. Neste caso, por detrás da cortina ecológica se encontraria em cena uma profunda crise ambiental.

A solução para a crise ambiental passa pela mudança do objetivo fundamental da sociedade moderna. O objetivo não pode ser a acumulação de capital, porque este propósito leva à competição acirrada e, consequentemente, à degradação ambiental. O caso de Páscoa, mesmo em um contexto diferente do encontrado na sociedade moderna, demonstra detalhadamente o que a competição exagerada pode desencadear. O objetivo primordial precisa ser cooperativo. Isso não significa que a competição será extirpada, até mesmo porque isso não seria possível, apenas que ela deixaria de ocupar posição de destaque na sociedade moderna. Esta alteração não será fácil. A competição, principalmente por força do capitalismo, tem raízes profundas. Por isso mesmo, a mudança precisa ser gradual e de baixo para cima. Um caminho para isso pode ser o estabelecimento de cooperativas que tenham como fundamento o respeito pelo meio ambiente. Atualmente, existem muitas espalhadas pelo mundo, sendo que em alguns países o sistema cooperativo se desenvolveu significativamente,

como Suécia e Inglaterra. É preciso incentivar a constituição de mais cooperativas - os grupos que lutam pela natureza teriam papel importante aqui - a ponto de que estas sejam capazes de encaminhar a transição para o objetivo primordial cooperativo. Este pode ser um caminho virtuoso para se alcançar o reequilíbrio na relação entre homem e natureza.

\section{CONSIDERAÇÕES FINAIS}

A crise ambiental contemporânea é complexa. A natureza apresenta indícios de desgaste, necessitando ser preservada, mas o que se nota é que a pressão sobre os recursos naturais só aumenta. Isso ocorre por força do produtivismo e do consumismo que, a cada novo ciclo produtivo, revitalizam-se em busca de mais acumulação de capital. Isso não representaria nenhum problema, se a produção e consumo não fossem profundamente 
dependentes dos recursos naturais, alguns, cabe destacar, não renováveis. O cenário que se apresenta certamente não é bom, mas o cenário futuro pode ser ainda mais dramático, se a acumulação de capital permanecer como objetivo primordial da sociedade moderna.

O caso da Ilha de Páscoa, respeitadas suas peculiaridades, apresenta indícios do que ocorre, quando não se respeita os limites da natureza. Certamente é o momento de mudar, mas essa mudança não será fácil. Assim como Páscoa, a sociedade moderna se encontra profundamente envolvida em um processo de competição. Cada indivíduo da sociedade luta por toda a sua vida para adquirir o máximo de capital para comprar o máximo de coisas. Esta lógica não é coerente com os limites da natureza. É preciso estabelecer uma nova lógica, uma lógica mais cooperativa, na qual o fim das atividades humanas não seja a acumulação de capital. Uma lógica que preserve os direitos dos seres humanos, mas que também reconheça o direito da natureza, dos animais e de outras espécies.

Esta argumentação tende a indicar a proposição da necessidade do fim do capitalismo. Talvez, posteriormente, chegue-se mesmo a esta consideração. Por ora, o que se pode concluir é que a sociedade moderna precisa interromper a competição exacerbada. Fazer o que Páscoa não fez. Isso é fundamental para interromper as irracionalidades humanas que têm ocorrido nos dias atuais. É preciso definir um novo objetivo primordial, predominantemente cooperativo. Como não é sensato presumir que esta mudança ocorra prontamente, o que se pode fazer no momento é incentivar o fortalecimento do cooperativismo na sociedade moderna. Espera-se que esta transição ocorra naturalmente ao longo do tempo ou será que, a exemplo de Páscoa, a sociedade moderna continuará a permitir que a racionalidade ecológica seja suplantada por outras racionalidades? Os próximos episódios da história da sociedade moderna decerto trarão esclarecimentos a esse respeito.

\section{REFERÊNCIAS}

DIAMOND, J. Colapso: como as sociedades escolhem o fracasso ou o sucesso. Rio de Janeiro: Editora Record, 2009.

MEAD, M. Cooperation and competition among primitive peoples. Boston: Beacon Press, 1961.

OGBURN, W. F.; NIMKOFF, M. F. Cooperação, competição e conflito. In: CARDOSO, F.H; IANNI, O. Homem e sociedade: leituras básicas. São Paulo: Editora Nacional, 1965.

PARK, R. E.; BURGESS, E. Competição, Conflito, Acomodação e Assimilação. Revista Brasileira de Sociologia da Emoção, v. 13, n. 38, 2014. 


\section{Como Referenciar este Artigo, conforme ABNT:}

GODOY, D. F. S. Ilha De Páscoa: Experiências do Passado Como Meio Para Pensar a Crise Ambiental Contemporânea. Rev. FSA, Teresina, v.18, n. 12, art. 7, p. 124-138, dez. 2021.

\begin{tabular}{|l|c|}
\hline \multicolumn{1}{|c|}{ Contribuição dos Autores } & D. F. S. Godoy \\
\hline 1) concepção e planejamento. & $X$ \\
\hline 2) análise e interpretação dos dados. & $X$ \\
\hline 3) elaboração do rascunho ou na revisão crítica do conteúdo. & $X$ \\
\hline 4) participação na aprovação da versão final do manuscrito. & $X$ \\
\hline
\end{tabular}

